\title{
Research on the Economic Development Effect of Human Capital Investment
}

\author{
Shan Song ${ }^{1}$, Huiliang Zhang ${ }^{2}, \mathrm{Ke} \mathrm{Gao}^{3}$ \\ ${ }^{1}$ School of Public Finance and Tax, Central University of Finance and Economics, Beijing, P. R. China \\ ${ }^{2}$ Department of Accounting, Weifang Commercial College of Shandong, Weifang, P. R. China \\ ${ }^{3}$ School of Social Sciences, Tsinghua University, Beijing, P. R. China
}

Email address:

baiciron@163.com (Shan Song), zhlwfsx@ sina.com (Huiliang Zhang), gkfly $@$ 126.com (Ke Gao)

\section{To cite this article:}

Shan Song, Huiliang Zhang, Ke Gao. Research on the Economic Development Effect of Human Capital Investment. Humanities and Social Sciences. Vol. 8, No. 2, 2020, pp. 73-77. doi: 10.11648/j.hss.20200802.14

Received: March 11, 2020; Accepted: May 7, 2020; Published: May 29, 2020

\begin{abstract}
With the rapid development of knowledge economy and information age, human capital has gradually become the key factor to support the sustainable development of economy in modern society. It is an important part of government and social investment, which directly affects the strategy of building a strong country with talents and the coordinated development of economy and society. China is rich in labor resources, but due to the difference of natural endowment and economic development level, there are different levels of development imbalance of human capital among provinces and cities. This paper uses the data of 31 provinces, cities and autonomous regions from 2007 to 2017 to build a model, specifically demonstrates the impact of human capital investment on regional economic growth, analyzes the relationship between investment income and regional economic growth, and finally concludes that the level of human capital investment has a significant positive impact on the growth of regional per capita GDP, and puts forward suggestions on increasing the level of regional education investment, improving the policy of talent introduction, strengthening the investment in scientific and technological research and development, and deepening the reform and opening up, which can provide useful reference for scientific planning of China's future human capital development strategy and regional social and economic development.
\end{abstract}

Keywords: Human Capital, Investment Efficiency, Regional Economic Development, Model Analysis, Nfluence Factor

\section{Research Background}

China is rich in labor resources, but there is a relative shortage of human capital, and there are different levels of development imbalance in various provinces. To optimize the rational and efficient allocation of human capital and obtain higher output of human capital with lower input of human capital is not only an important content of implementing the strategy of strengthening the country with talents, but also an important way to promote the coordinated development of economy. Therefore, through the study of the impact of human capital investment on regional economic growth, it is of great significance to find out the problems existing in the investment of human capital in China, and actively start to improve the utilization efficiency of human capital in China, so as to promote the sustainable development of China's economy and further enhance the country's soft power.
Human capital refers to the sum of knowledge, skills, physical strength and other quality factors with economic value existing in human body [1]. According to the theory of human capital put forward by Wang and Yao [2] and Fleisher [3], social and unit production investment not only forms material capital such as assets and equipment, but also forms human capital existing in workers, contributing to economic growth. Human capital investment has different performance in different fields and regions. Many scholars in China have carried out various researches, mainly focusing on three aspects [4]:

First, the relationship between human capital and economic growth. Many studies show that the level of economic develoapment is an important factor affecting human capital investment [5], and there is a positive correlation between human capital and economic growth. Kevin harriott [6] believes that higher education plays a key role in the economic growth of developed and developing 
countries, and that human capital with high-tech capabilities has a significant positive correlation with economic growth. Chang Qingqing and Zhong Weizhou [7] studied whether human capital has a significant impact on scientific and technological innovation. They found that the improvement of human capital will significantly enhance the impact of Internet use on scientific and technological innovation.

Second, the efficiency of regional human capital investment. Zhang Wuqian and $\mathrm{Li}$ Rui [8] used data envelopment analysis (DEA) to measure the total factor investment efficiency and provincial differences of China's human capital, and proposed that the total factor investment efficiency index of China's human capital showed a downward trend on the whole, and technological progress was the main reason for the provincial differences; Li Ping [9] comprehensively studied the regional differences in the efficiency of human capital investment by using the panel data of 31 provinces in China from 2000 to 2015, and found that the regional development level will significantly improve the local human capital investment. In the provinces with high per capita income level, the level of education for each person is relatively high.

Third, research on the influencing factors. Human capital investment is affected by macro environment and micro individual, social demand, education system and health care system. Bai Yong and Ma Yueru [10] found that skills training, residents' economic conditions, foreign trade and institutional changes have significant impact on the efficiency of human capital investment. Gao Qiang [11] studied the efficiency of human capital investment in rural areas of China, and found that the technical efficiency of human capital investment in rural areas of China is low, showing regional differences; the income level of rural residents, institutional changes, information technology level, etc. help to improve the efficiency of rural human capital investment, and skills training and population migration restrict the efficiency of rural human capital investment.

\section{Model Selection}

There are many ways to invest in human capital, including education expenditure, health care expenditure, domestic labor mobility expenditure [12]. Combined with the actual situation in China, To study the impact of human capital investment on regional economic development, it is proposed to select per capita GDP as the proxy indicator of regional economic development level, per capita government education expenditure, per 10000 ordinary schools, per capita government science and technology expenditure, per capita medical and health expenditure, per capita government social security and employment expenditure as the proxy indicators of human capital investment, and select the urban-rural income gap As a control variable, using the relevant data of 31 provinces, cities and autonomous regions from 2007 to 2017 [13], the following regression model is established:

$$
\begin{gathered}
\mathrm{Y}_{\mathrm{it}}=\mathrm{C}_{\mathrm{it}}+\alpha_{1} * \mathrm{X} 1_{\mathrm{it}}+\alpha_{2} * \mathrm{X} 2_{\mathrm{it}}+\alpha_{3} * \mathrm{X} 3_{\mathrm{it}}+\alpha_{4} * \mathrm{X} 4_{\mathrm{it}}+ \\
\alpha_{5} * \mathrm{X} 5_{\mathrm{it}}+\alpha_{6} * \mathrm{X} 6_{\mathrm{it}}+\alpha_{7} * \mathrm{X} 7_{\mathrm{it}}+\alpha_{8} * \mathrm{X} 8_{\mathrm{it}}
\end{gathered}
$$

\begin{tabular}{|c|c|c|c|c|}
\hline Variable type & Variable symbol & Variable name & $\begin{array}{l}\text { Number of } \\
\text { provincial regions }\end{array}$ & $\begin{array}{l}\text { Observation } \\
\text { number }\end{array}$ \\
\hline Explained variable & $\mathrm{Y}_{\text {it }}\left(\mathrm{GDP} \_\mathrm{per}_{\mathrm{it}}\right)$ & Per capita GDP & 31 & 341 \\
\hline Explanatory variable & $\mathrm{X} 1_{\text {it }}$ (gov_edu_per ${ }_{\text {it }}$ ) & Per capita government expenditure on Education & 31 & 341 \\
\hline Explanatory variable & $\mathrm{X} 2_{\text {it }}\left(\right.$ school_per $\left._{\text {it }}\right)$ & Number of ordinary schools per 10000 people & 31 & 341 \\
\hline Explanatory variable & $\mathrm{X} 3_{\text {it }}\left({\left.\text { gov_R } \& D \_p e r_{\text {it }}\right)}\right.$ & Per capita government expenditure on science and technology & 31 & 341 \\
\hline Explanatory variable & $\mathrm{X} 4_{\text {it }}\left(\right.$ medical_per $\left.{ }_{\text {it }}\right)$ & Per capita medical and health expenditure & 31 & 341 \\
\hline Explanatory variable & $\mathrm{X} 5_{\text {it }}$ (insurance_per ${ }_{\text {it }}$ ) & $\begin{array}{l}\text { Per capita government social security and employment } \\
\text { expenditure }\end{array}$ & 31 & 341 \\
\hline control variable & $\mathrm{X} 6_{\text {it }}$ (income_gap ${ }_{\text {it }}$ ) & Income gap between urban and rural areas & 31 & 341 \\
\hline control variable & $\mathrm{X} 7_{\text {it }}$ (Total_imp_and_exp $\mathrm{pit}_{\mathrm{it}}$ ) & total imports and exports & 31 & 341 \\
\hline control variable & $\mathrm{X}_{\text {it }}$ (Urbanization $\left._{\mathrm{it}}\right)$ & $\begin{array}{l}\text { Urbanization level (Select the proportion of urban population } \\
\text { as the proxy index) }\end{array}$ & 31 & 341 \\
\hline
\end{tabular}

Table 1. Variable interpretation.

\section{Empirical Analysis}

\subsection{Descriptive Statistics}

Table 2. Descriptive statistics.

\begin{tabular}{llllll}
\hline Variable & Obs & Mean & Std. Dev. & Min & Max \\
\hline Y1 & 341 & 42000 & 23700 & 7878 & 129000 \\
X1 & 341 & 1519.164 & 867.5712 & 348.0982 & 6741.751 \\
X2 & 341 & .5401 & .1289 & .3392 & .9246 \\
X3 & 341 & 201.3664 & 264.4637 & 20.003 & 1666.32 \\
X4 & 341 & 654.3074 & 403.3946 & 93.1503 & 2783.258 \\
X5 & 341 & 1191.057 & 807.7823 & 194.9378 & 6298.187 \\
X6 & 341 & 10900 & 4342.859 & 3187.02 & 33000 \\
X7 & 341 & 2315.514 & 7770.484 & 3.9348 & 101000 \\
X8 & 341 & 53.1682 & 14.2391 & 21.5 & 89.6 \\
\hline
\end{tabular}

Through the descriptive statistics in Table 2, it can be seen that in the sample data selected in this paper, the explained variables, explained variables and control variables have no abnormal values, so it can be considered that the analyzed data are true and objective.

\subsection{Empirical Test}

In order to test the scientificity and feasibility of the above variables selection, and to prevent the instability of variables, this study first conducted unit root test and cointegration test on variables, and completed the necessary regression by Using Stata software. Unit root test and cointegration test are as follows: 
Table 3. Unit root test.

\begin{tabular}{lll}
\hline variable & Ips test & Cips test \\
\hline GDP_per $_{\text {it }}$ & 9.5033 & 0.156 \\
$\Delta$ GDP_per $_{\text {it }}$ & $-2.3319^{* * *}$ & -0.922 \\
gov_edu_per $_{\text {it }}$ & 5.8415 & -1.167 \\
gov_exp_per $_{\text {it }}$ & $-4.9540^{* * *}$ & $-2.319^{* * *}$ \\
school_per $_{\text {it }}$ & $-4.3665^{* * *}$ & -0.894 \\
$\Delta$ school_per $_{\text {it }}$ & -0.6465 & $-2.207^{* * *}$ \\
gov_R\&D_per $_{\text {it }}$ & 10.8163 & -1.204 \\
$\Delta$ gov_R\&D_per $_{\text {it }}$ & $-3.6209^{* * *}$ & $-2.333^{* * *}$ \\
medical_per $_{\text {it }}$ & 13.9979 & -1.163 \\
medical_per $_{\text {it }}$ & $-5.9604^{* * *}$ & $-2.381^{* * *}$ \\
insurance_per $_{\text {it }}$ & 16.8522 & $-1.500^{*}$ \\
$\Delta$ insurance_per $_{\text {it }}$ & $-5.0172^{* * *}$ & $-3.276^{* * *}$ \\
income_gap $_{\text {it }}$ & $-2.0488^{* *}$ & 0.485 \\
income_gap $_{\text {it }}$ & $-6.6077^{* * *}$ & -0.943 \\
Total import and export $_{\text {it }}$ & $-4.7837^{* * *}$ & $-2.342^{* * *}$ \\
Urbanization $_{\text {it }}$ & -5.8123 & $-2.661^{* * *}$ \\
\hline
\end{tabular}

variables are generally stable, but there are individual variables that can not meet the two kinds of stationarity tests at the same time, so the following cointegration tests are conducted:

Table 4. Cointegration test.

\begin{tabular}{lll}
\hline & Statistic & p-value \\
\hline Modified Phillips-Perron & 8.9614 & 0.0000 \\
Phillips-Perron & -20.3766 & 0.0000 \\
Augmented Dickey-Fuller & -17.5597 & 0.0000 \\
\hline
\end{tabular}

After the cointegration test, the covariance matrix of the selected variables is calculated to judge the correlation between variables. The results of covariance matrix are shown in table 5:

It can be seen from the regression results that the above

Table 5. Covariance matrix.

\begin{tabular}{|c|c|c|c|c|c|c|c|c|c|}
\hline Variables & (Y) & (X1) & (X2) & (X3) & (X4) & (X5) & (X6) & (X7) & (X8) \\
\hline $\mathrm{Y}$ & 1.000 & & & & & & & & \\
\hline $\mathrm{X} 1$ & $0.629 * * *$ & 1.000 & & & & & & & \\
\hline $\mathrm{X} 2$ & $-0.662 * * *$ & $-0.385 * * *$ & 1.000 & & & & & & \\
\hline $\mathrm{X} 3$ & $0.830 * * *$ & $0.608 * * *$ & $-0.507 * * *$ & 1.000 & & & & & \\
\hline $\mathrm{X} 4$ & $0.558 * * *$ & $0.936^{* * *}$ & $-0.319 * * *$ & $0.527 * * *$ & 1.000 & & & & \\
\hline $\mathrm{X} 5$ & $0.484 * * *$ & $0.822 * * *$ & $-0.247 * * *$ & $0.477 * * *$ & $0.860 * * *$ & 1.000 & & & \\
\hline X6 & $0.662 * * *$ & $0.300 * * *$ & $-0.476 * * *$ & $0.760 * * *$ & $0.200 * * *$ & $0.203 * * *$ & 1.000 & & \\
\hline$X 7$ & -0.067 & 0.028 & $0.102 *$ & -0.036 & 0.074 & 0.082 & -0.041 & 1.000 & \\
\hline $\mathrm{X} 8$ & -0.055 & 0.080 & $0.100^{*}$ & 0.025 & $0.095^{*}$ & $0.089 *$ & 0.020 & $0.317 * * *$ & 1.000 \\
\hline
\end{tabular}

$* * * \mathrm{p}<0.01, * * \mathrm{p}<0.05, * \mathrm{p}<0.1$

It can be seen from the covariance matrix that the explained variable $\mathrm{y}$ has significant correlation with the explained variables $\mathrm{x} 1, \mathrm{X} 2, \mathrm{X} 3, \mathrm{x} 4, \mathrm{X} 5$ and $\mathrm{X} 6$, but not with $\mathrm{X} 7$ and $\mathrm{X} 8$.

\subsection{Fixed Effect and Random Effect Regression}

Table 6. Fixed effect and random effect regression.

\begin{tabular}{lll}
\hline & $(\mathbf{1})$ & $\mathbf{( 2 )}$ \\
\hline VARIABLES & Y1 fixation & Y1 random \\
\hline X1 & $3.1617 * * *$ & $3.6667 * * *$ \\
& $(1.1692)$ & $(1.2543)$ \\
X2 & $-17,726.9448 * *$ & $-24,555.4110^{* * *}$ \\
& $(8,038.5237)$ & $(6,607.6583)$ \\
X3 & $45.7963 * * *$ & $31.8189 * * *$ \\
& $(3.4857)$ & $(3.3728)$ \\
X4 & 2.0075 & $10.8458 * * *$ \\
& $(3.0413)$ & $(2.7489)$ \\
X5 & 0.2487 & -1.1629 \\
& $(0.9261)$ & $(0.9496)$ \\
X6 & $0.3389 * * *$ & $0.2956 * * *$ \\
& $(0.1043)$ & $(0.1134)$ \\
X7 & $0.0991 * *$ & $0.1641 * * *$ \\
& $(0.0397)$ & $(0.0425)$ \\
X8 & $1,311.6550 * * *$ & $756.4131 * * *$ \\
& $(132.1616)$ & $(72.7489)$ \\
Constant & $-37,746.7289 * * *$ & $-6,272.5351$ \\
& $(9,418.8882)$ & $(6,622.1366)$ \\
Observations & 341 & 341 \\
R-squared & 0.9125 & 31 \\
Number of provinces & 31 & \\
\hline
\end{tabular}

The empirical analysis shows that most of the regression variables are significant, and the level of human capital investment has a significant positive impact on the growth of regional per capita GDP. In relatively developed areas, the per capita GDP level is relatively high, the amount of investment in human capital is relatively large, and the per capita education level is naturally relatively high. Analysis of the regression results of each variable shows that:

a) The per capita government expenditure on Education (x1) has a positive impact on per capita GDP and is significant at the level of $1 \%$. The higher the proportion of education expenditure is, the higher the per capita GDP is [14]. Per capita government expenditure on education is the main indicator of human capital investment, which shows that human capital investment has a positive impact on per capita GDP. Positive and significant results provide direction for regional government investment.

b) The number of ordinary schools per 10000 people (x2) has a negative impact on per capita GDP and is significant at the level of $5 \%$. The author believes that the construction investment cycle of the school is long, and the return cycle of investment is long. The investment in the construction of the school squeezes out the investment in the people's livelihood in a short time, and reduces the per capita GDP in a short time.

c) The per capita government expenditure on science and Technology (x3) has a positive impact on per capita GDP, which is significant at the level of $1 \%$. Different from the 
per capita government expenditure on education, government expenditure on science and technology is a direct investment in science and technology, closer to the industrial end, with shorter reporting cycle and higher level of significance. It can be seen from the regression results that the coefficient of per capita government science and technology expenditure as an explanatory variable is 45.7963 , which has a greater impact on per capita GDP.

d) Health expenditure per capita ( $x 4$ ) has a positive impact on GDP per capita, but it is not significant in the fixed effect model. In the random effect model, there is a significant positive effect, and the significance level is $1 \%$. The author thinks that the per capita medical and health expenditure is an important indicator of human capital investment, but because this factor mainly plays a protective role, its impact path on per capita GDP is more complex and has a long-term nature, but the importance of such expenditure cannot be ignored.

e) Government social security and employment expenditure per capita (x5) have a positive impact on GDP per capita, but they are not significant under both fixed effect and random effect. As the same as the per capita medical and health expenditure, social security and employment expenditure are the guarantee expenditure for human capital, not the investment directly affecting per capita GDP.

f) The income gap between urban and rural areas (x6) has a positive impact on per capita GDP, which is significant at the level of $1 \%$. From the regression results, we can see that the impact coefficient of urban-rural income gap on per capita GDP is 0.3389 , that is, the higher the income gap, the higher the per capita GDP.

g) Total import and export (X7) has a positive impact on per capita GDP, which is significant at the $10 \%$ level. The total amount of import and export is an indicator of a region's participation in the level of globalization, that is, the level of globalization has a positive and significant impact on regional per capita GDP.

\section{Conclusions and Suggestions}

a) We will increase investment in regional education. The results show that human capital investment will promote the development of regional economy, and increase regional education investment can better cultivate local talents and gain advantages in talent competition.

b) We will improve the policy of talent introduction. In addition to increasing regional investment to cultivate local talents, increasing investment in foreign talents is also an important way for a region to invest in human capital, which has become a consensus of all walks of life. Only with sound policy support and guarantee can it emerge in the "war for talents". At the same time, in the process of improving the efficiency of human capital investment, it is necessary to implement the strategy of regional coordinated development, actively explore the new mode of urban cooperation, and realize the division of labor and the complementary development of industries through the integration of resources at the regional level [15].

c) We will vigorously support investment in scientific and technological research and development. From the above regression results, it can be seen that the per capita government expenditure on science and technology will bring high returns. Different from general human capital investment, investment in science and technology not only has a short return period, but also has a higher return rate and high externality, which can better promote social development.

d) We will deepen reform and opening up, and promote faster and better development of import and export trade. The theory of international trade has proved that deepening international cooperation can promote the economic development of the region, promote and build regional characteristic industrial chain, and promote economic development.

\section{References}

[1] Yu Yin, Yin Qingshuang. Identification and pricing of human capital investment efficiency and risk in capital market [J]. Research on financial issues, 2018 (11): 114-121.

[2] Wang, Y., Yao, Y. Sources of China's Economic Growth 1952 - 1999: Incorporating Human Capital Accumulation [J]. China Economic Review, 2003, 14 (1): 32-52.

[3] Fleisher, B., Li, H., Zhao, M. Q. Human Capital, Economic Growth, and Regional Inequality in China [J]. Journal of Development Economics, 2010, 92 (2): 215-231.

[4] Lu Xinwen, Cheng Yi, Wang Miaomiao. Analysis of human capital investment efficiency and its influencing factors in the Yangtze River Delta urban agglomeration [J]. Journal of Jianghan University (SOCIAL SCIENCE EDITION), 2019, 36 (05): $91-100+128$.

[5] Li Yaqun, Duan Wanchun, sun Yonghe, et al. Identification and analysis of main influencing factors of human capital investment in underdeveloped areas [J]. Soft science, 2013 (6).

[6] TSAI C L, HUNG M C, HARRIOTT K. Human capital composition and economic growth [J]. International Journal of Social Economics, 2010, 99 (1).

[7] Chang Qingqing, Zhong Weizhou. Empirical Study on the threshold effect of Internet, human capital and technological innovation [J]. Statistics and decision making, 2018, 34 (24): 101-104.

[8] Wu Yi Zhang, Rui Li. A study on the dynamic changes of the efficiency of all factors investment in human capital and the provincial differences $[\mathrm{J}]$. Science and technology and economy, 2016 (1).

[9] Li Ping, Zhang Liu, pan Hongyan. An Empirical Study on the impact of regional differences in human capital investment on income [J]. Nandu academic circle, 2019, 39 (01): 108-115. 
[10] Bai Yong, Ma Yueru. Empirical analysis on the efficiency of human capital investment and its influencing factors in China [J]. Statistics and decision, 2013 (14).

[11] Gao Qiang, Xu Hanxiao, Li Xianbao. Research on the factors influencing the efficiency of rural human capital investment in China [J]. World agriculture, 2018, 475 (11): 219-226.

[12] Gary S. Becker. Human capital: a theoretical and empirical analysis of education in particular [M]. Trans. Liang Xiaomin, Beijing: Peking University Press, 1987: 1.
[13] Data source: China Statistical Yearbook 2007-2017.

[14] Du Peng. The impact of government education expenditure on per capita GDP: An Empirical Analysis Based on OECD countries [J]. China's collective economy, 2018 (32): 42-43.

[15] Zhang Xueliang, Chen Jianjun, Wei Wei, fan Jianyong, Mao Yanhua. Accelerating the development of regional integration in the Yangtze River Delta [J]. Regional economic review, 2019 (2). 